\title{
HISTOPATHOLOGICAL PROFILE OF MEDIASTINAL LESIONS- A FIVE-YEAR STUDY FROM A TERTIARY CARE CENTRE IN SOUTH INDIA
}

\author{
Nihad Abdul Razak Amanullah¹, Letha Vilasiniamma², Lillykutty Pothen³, Sankar S4 \\ ${ }^{1}$ Assistant Professor, Department of Pathology, S. R. Medical College and Research Centre, Vennicode PO, Akathumuri, Varkala, \\ Trivandrum. \\ ${ }^{2}$ Additional Professor, Department of Pathology, Government Medical College, Kottayam. \\ ${ }^{3}$ Additional Professor, Department of Pathology, Government Medical College, Kottayam. \\ ${ }^{4}$ Professor, Department of Pathology, Government Medical College, Kottayam.
}

\section{ABSTRACT}

\section{BACKGROUND}

The mediastinum is the central limited space of the thoracic cavity, which houses a variety of neoplastic and non-neoplastic lesions. Accurate diagnosis is warranted owing to the variable therapeutic and prognostic implications. The aims of this study are to study the frequency and distribution of mediastinal tumours and tumour-like lesions and to study the histomorphological patterns of the various mediastinal lesions.

\section{MATERIALS AND METHODS}

This is a retrospective descriptive study of all mediastinal tumours/ biopsy specimens received in Department of Pathology, Govt. Medical College, Kottayam, from January $1^{\text {st }} 2012$ to December 31 st 2016. The epidemiological profile, relevant clinical and laboratory details and histomorphology were studied and the tumours were classified according to the latest WHO classification.

\section{RESULTS}

Of the 157 cases studied, 79 were males and 78 were females; 66\% (103 cases) of the lesions were found in the anterior mediastinum, 12\% (33 cases) in the middle mediastinum, 8\% (13 cases) in the posterior mediastinum and 5\% (8 cases) in the superior mediastinum. The most common presenting symptoms were pressure symptoms like cough, dyspnoea and vague chest pain (102) followed by paraneoplastic symptoms like myasthenia gravis, red cell aplasia and hyperparathyroidism. Eight cases were detected incidentally. The thymic epithelial tumours accounted for 31\% (48), germ cell tumours 9\% (14), lymphomas 4\% (6), soft tissue tumours 15\% (23), ectopic tumours 2\% (4) and metastasis 5\% (8), while non-neoplastic accounted for 34\% (54) of the lesions. The age group of the patients for each diagnostic category was found to be of significance. IHC was done for classification of certain thymomas and lymphomas.

\section{CONCLUSION}

This study reflects the incidence of different mediastinal lesions in South India and attempts to describe the histomorphological patterns and their clinical correlation.

\section{KEYWORDS}

Mediastinum, Thymoma, Lymphoma, Germ Cell Tumours, Soft Tissue Tumours.

HOW TO CITE THIS ARTICLE: Amanullah NAR, Vilasiniamma L, Pothen L, et al. Histopathological profile of mediastinal lesions- a five-year study from a tertiary care centre in south India. J. Evolution Med. Dent. Sci. 2017;6(84):5865-5869, D0I: $10.14260 /$ jemds $/ 2017 / 1274$

\section{BACKGROUND}

The mediastinum is the central portion of the thoracic cavity, limited by pleural cavities laterally, thoracic inlet superiorly and the diaphragm inferiorly. It is further divided into superior, anterior, middle and posterior compartments. ${ }^{1}$ Even though mediastinal tumours are rare comprising only $3 \%$ of tumours occurring within the chest, it is a veritable Pandora's Box within which a variety of both neoplastic and non-neoplastic lesions may develop.

'Financial or Other Competing Interest': None.

Submission 11-09-2017, Peer Review 07-10-2017,

Acceptance 12-10-2017, Published 19-10-2017.

Corresponding Author:

Dr. Letha Vilasiniamma,

Additional Professor,

Department of Pathology,

Government Medical College,

Kottayam, Gandhinagar P.O.,

Kottayam District, Kerala,

India.

E-mail:drlethav@gmail.com

DOI: $10.14260 /$ jemds $/ 2017 / 1274$
The recent WHO classification of the tumours of the thymus and mediastinum (4th edition Lyon 2015) includes epithelial tumours (thymomas, thymic carcinomas, thymic neuroendocrine tumours, combined thymic carcinomas), germ cell tumours (seminoma, embryonal carcinoma, yolk sac tumour, choriocarcinoma, teratoma, mixed tumours, germ cell tumours with somatic type or haematological malignancy), lymphomas, histiocytic and dendritic cell neoplasm, myeloid sarcoma and extramedullary AML, soft tissue tumours (thymolipoma, lipoma, liposarcoma, synovial sarcoma, vascular neoplasms and neurogenic tumours), ectopic tumours of the thymus and metastasis to thymus and mediastinum. ${ }^{2}$

The most common lesions in adults are thymoma and lymphomas, while neurogenic tumours and germ cell tumours are the common lesions in children. Other rare tumours include benign cysts including hydatid cysts, benign and malignant soft tissue tumours and neuroendocrine tumours. ${ }^{1}$ 
This study was conducted to assess the epidemiological profile, frequency, distribution and histomorphological findings of the various mediastinal lesions in a tertiary care hospital over a period of 5 years.

\section{MATERIALS AND METHODS}

This is a retrospective descriptive study conducted in the Department of Pathology of a tertiary care teaching hospital of South India over a period of 5 years from January $1^{\text {st }} 2012$ to December 31st 2016. All mediastinal tumours/ biopsy received in Dept. of Pathology, Government Medical College, Kottayam, were included in the study. Lung, pleural, oesophageal, vascular and non-diagnostic lesions were excluded. A total of 157 cases were studied.

Biopsy records from January 2012 to December 2016 were scrutinised for all the mediastinal mass tumours/ biopsy specimens. The epidemiological profile, relevant clinical and laboratory details and histomorphology were studied from the retrieved request forms, slides and case records using a proforma.

The slides ( $\mathrm{H}$ and $\mathrm{E}$, special stains, IHC) and biopsy reports were retrieved and scrutinised. The neoplasms were classified according to WHO classification of tumours of the thymus and mediastinum (4th edition Lyon 2015), while nonneoplastic lesions were given a separate categorisation.

All relevant data were recorded meticulously with proforma, coded appropriately and analysed with SPSS version 16.

\section{RESULTS}

Of the 157 cases included in our study, 79 were males and 78 females with a male-to-female ratio of $1: 1$. In this study, $66 \%$ (103) of the lesions were found in the anterior mediastinum, $12 \%$ (33) in the middle mediastinum, $8 \%$ (13) in the posterior mediastinum and $5 \%$ (8) in the superior mediastinum. (Figure 1).

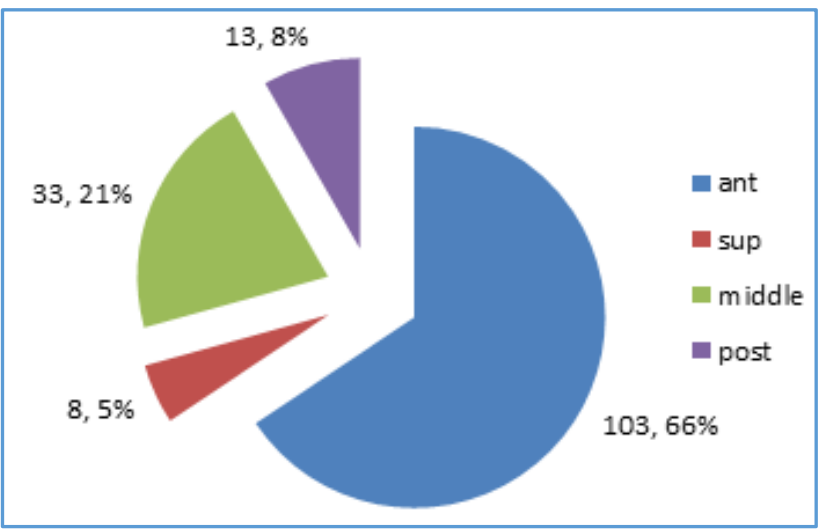

Figure 1. Distribution of Lesions in the various Compartments

The most common presenting symptoms were pressure symptoms like cough, dyspnoea and vague chest pain (102 cases) followed by paraneoplastic symptoms like myasthenia gravis, red cell aplasia. Hypercalcaemia was seen in the ectopic parathyroid tumours of the thymus. Eight cases were detected incidentally (Figure 2).

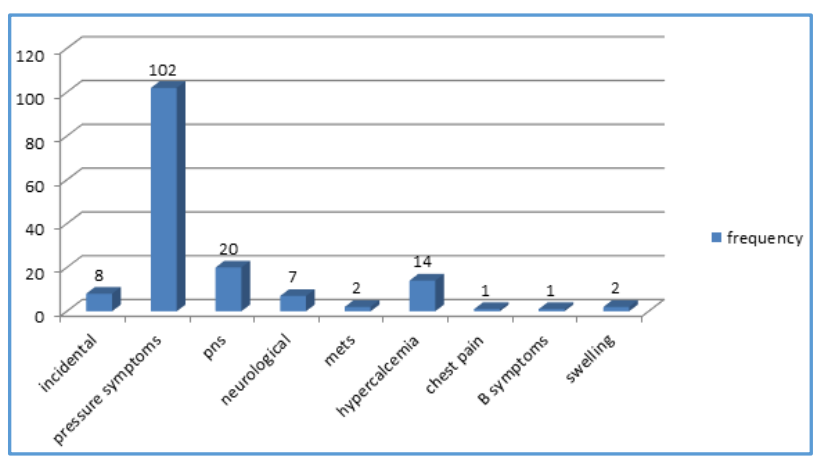

Figure 2. Presenting Complaints of Patients with Mediastinal Masses

Pressure symptoms were the most common clinical feature in thymic tumours, germ cell tumours and lymphomas. Paraneoplastic syndromes like myasthenia gravis, neurological symptoms were also seen among the thymic lesions. The neural soft tissue tumours presented with neurological deficits and pressure symptoms. Ectopic tumours of the thymus were associated with hypercalcaemia and pressure symptoms. Non-neoplastic lesions had a varied presentation.

$66 \%$ cases were neoplastic and classified according to the 2015 WHO classification of tumours of the thymus and mediastinum. Remaining $34 \%$ (54 cases) were nonneoplastic. The frequency and distribution of the broad categories of the lesions are given in Figure 3.

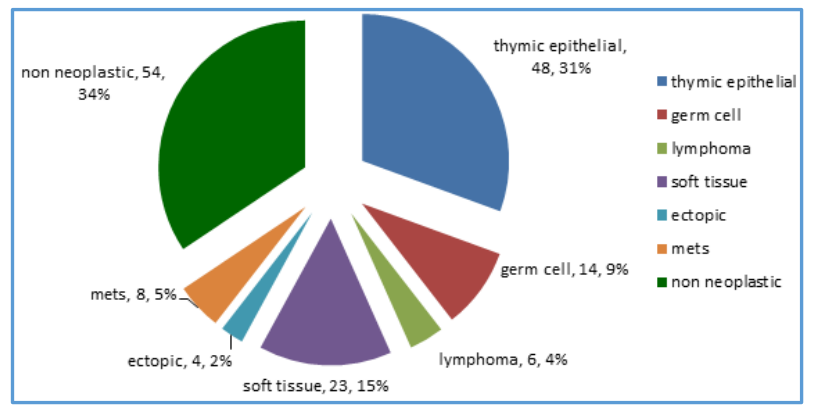

Figure 3. Histopathological Diagnosis of Mediastinal Lesions

The anterior mediastinum accommodated all the germ cell tumours and $96 \%$ of the thymic epithelial tumours, while soft tissue tumours which included the neurogenic tumours were seen predominantly in the posterior compartment (Table 1).

\begin{tabular}{|c|c|c|c|c|c|}
\hline Diagnosis & Anterior & Superior & Middle & Posterior & Total \\
\hline $\begin{array}{c}\text { Thymic } \\
\text { epithelial } \\
\text { tumours }\end{array}$ & $46(95.8 \%)$ & 0 & $2(4.2 \%)$ & 0 & 48 \\
\hline Germ cell & $14(100 \%)$ & 0 & 0 & 0 & 14 \\
\hline Lymphoma & $2(33.3 \%)$ & 0 & $4(66.7 \%)$ & 0 & 6 \\
\hline Soft tissue & $10(43.5 \%)$ & $2(8.7 \%)$ & 0 & $11(47.8 \%)$ & 23 \\
\hline Ectopic & $3(75.0 \%)$ & 0 & 0 & $1(25.0 \%)$ & 4 \\
\hline Metastasis & $1(12.5 \%)$ & $4(50.0 \%)$ & $3(37.5 \%)$ & 0 & 8 \\
\hline $\begin{array}{c}\text { Non- } \\
\text { neoplastic }\end{array}$ & $27(50.0 \%)$ & $2(3.7 \%)$ & $\begin{array}{c}24 \\
(44.4 \%)\end{array}$ & $1(1.9 \%)$ & 54 \\
\hline Total & $\mathbf{1 0 3}$ & $\mathbf{8}$ & $\mathbf{3 3}$ & $\mathbf{1 3}$ & $\mathbf{1 5 7}$ \\
\hline In \% & $\mathbf{6 5 . 6 \%}$ & $\mathbf{5 . 1 \%}$ & $\mathbf{2 1 . 0 \%}$ & $\mathbf{8 . 3 \%}$ & $\begin{array}{c}\mathbf{1 0 0 . 0} \\
\mathbf{\%}\end{array}$ \\
\hline
\end{tabular}

Table 1. Distribution of the various Mediastinal Lesions in each Compartment 
The thymic neoplasms were seen in the $4^{\text {th }}$ to the $7^{\text {th }}$ decade. The germ cell tumours were seen from the $2^{\text {nd }}$ to $6^{\text {th }}$ decade. The lymphomas were more from the $2^{\text {nd }}$ to $4^{\text {th }}$ decade. Soft tissue tumours varied from the first to the sixth decade with neural tumours more in the paediatric age group. The ectopic tumours were common in the $3^{\text {rd }}$ to $5^{\text {th }}$ decade, while metastasis were seen from $5^{\text {th }}$ to $8^{\text {th }}$ decade. Non-neoplastic lesions were seen in all the age groups (Table 2).

\begin{tabular}{|c|c|c|c|c|c|c|c|c|c|}
\hline Diagnosis & \multicolumn{8}{|c|}{ Age in Decades } \\
\hline & $1^{\text {st }}$ & $2^{\text {nd }}$ & $3^{\text {rd }}$ & $4^{\text {th }}$ & $5^{\text {th }}$ & $6^{\text {th }}$ & $7^{\text {th }}$ & $8^{\text {th }}$ & Total \\
\hline $\begin{array}{c}\text { Thymic epithelial } \\
\text { tumours }\end{array}$ & 1 & 0 & 1 & 10 & 16 & 10 & 9 & 1 & 48 \\
\hline Germ cell & 0 & 3 & 4 & 2 & 3 & 2 & 0 & 0 & 14 \\
\hline Lymphoma & 0 & 1 & 3 & 1 & 0 & 0 & 0 & 1 & 6 \\
\hline Soft tissue & 5 & 5 & 1 & 4 & 2 & 5 & 1 & 0 & 23 \\
\hline Ectopic & 0 & 0 & 1 & 2 & 1 & 0 & 0 & 0 & 4 \\
\hline Metastasis & 0 & 0 & 0 & 0 & 2 & 2 & 1 & 3 & 8 \\
\hline Non-neoplastic & 6 & 6 & 9 & 7 & 9 & 12 & 4 & 1 & 54 \\
\hline Total & $\mathbf{1 2}$ & $\mathbf{1 5}$ & $\mathbf{1 9}$ & $\mathbf{2 6}$ & $\mathbf{3 3}$ & $\mathbf{3 1}$ & $\mathbf{1 5}$ & $\mathbf{6}$ & $\mathbf{1 5 7}$ \\
\hline In \% & 7.6 & 9.6 & 12.1 & 16.6 & 21 & 19.7 & 9.6 & 3.8 & \\
\hline Table 2. Age Distribution of the Broad Categories of \\
Mediastinal Lesions \\
\hline
\end{tabular}

Analysis of the 48 thymic epithelial tumours showed an M: F ratio of 1: 0.9. Majority 79\% (38 cases) presented with pressure symptoms like cough, dyspnoea and vague chest discomfort, while $21 \%$ (10) of them presented with paraneoplastic syndromes like myasthenia gravis. Most of them were in the anterior mediastinum $(46,95.8 \%)$ with some extending to the superior mediastinum (2, 4.2\%); $75 \%$ of the cases were in the age group of 20 - 50 years (Figure 4).

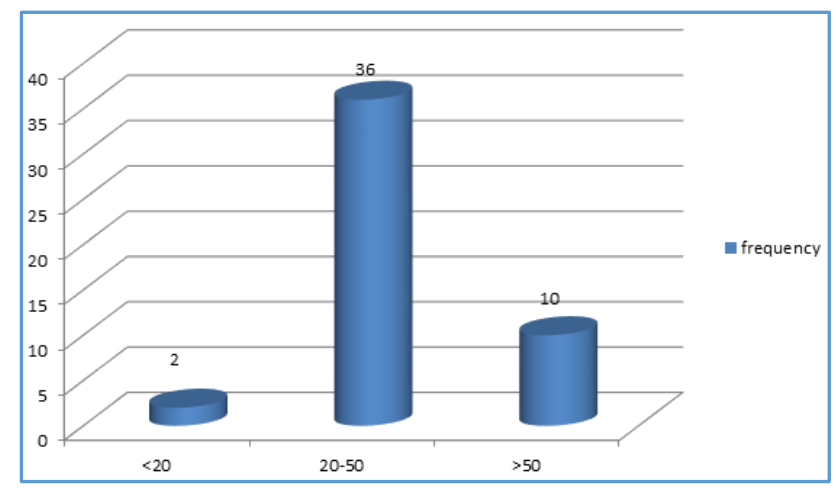

Figure 4. Age Group of the various Thymic Epithelial Lesions

Histopathological examination of the thymic tumours showed that $A B$ thymomas $(18,38 \%)$ were the most common thymomas followed by A, B1, B2 and B3 and a case of sclerosing thymoma. Most of the thymomas were Masaoka stage 1 or 2 . There were 8 cases of thymic carcinoma, 2 cases of sarcomatoid carcinoma, 1 case of hepatoid carcinoma, atypical carcinoid and large cell neuroendocrine carcinoma each (Figure 5).

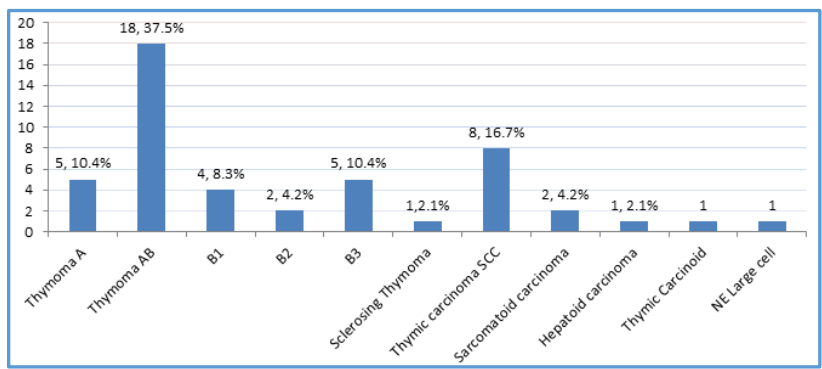

Figure 5. Histopathological Diagnosis of Thymic Epithelial Lesions

Of the 14 germ cell tumours analysed, 10 cases were seen in females $(71.4 \%)$ and 4 cases in males; $79 \%$ of the Germ cell tumours (11 cases) presented with pressure symptoms, while $21 \%$ were asymptomatic (3 cases of mature cystic teratomas). All germ cell tumours were confined to the anterior mediastinum. Dermoid cysts were the most common lesion. Histopathology showed a case of malignant mixed germ cell tumour in a 38-year-old male with yolk sac and immature teratoma components.

Lymphomas presented with cough, hypercalcaemia and fever. There were 6 cases of lymphomas with a M:F ratio of 1:2. Pressure symptoms like cough, B symptoms and fever were the presenting complaints. Middle mediastinum followed by superior mediastinum was the common anatomical position. There were three cases of Hodgkin's lymphoma and one case each of PMLBCL, ALK + ALCL and a Grey Zone Lymphoma - B cell lymphoma unclassifiable with features of DLBCL and Hodgkin's Lymphoma.

Of the 23 soft tissue tumours analysed, $61 \%$ were seen in males with a male: female ratio of 1.5: 1 . Pressure symptoms like cough, dyspnoea and dysphagia were the most common presentation followed by chest pain; $78 \%$ were benign, while $22 \%$ were malignant.

\begin{tabular}{|c|c|c|}
\hline Diagnosis & No. of Cases & Percentage \\
\hline Thymolipoma & 1 & 4.3 \\
\hline Lipoma & 2 & 8.7 \\
\hline Solitary fibrous tumour & 1 & 4.3 \\
\hline Synovial sarcoma & 2 & 8.7 \\
\hline Lymphangioma & 2 & 8.7 \\
\hline Haemangioma & 1 & 4.3 \\
\hline Schwannoma & 5 & 21.7 \\
\hline Neurofibroma & 1 & 4.3 \\
\hline MPNST & 1 & 4.3 \\
\hline Ganglioneuroma & 2 & 8.7 \\
\hline Neuroblastoma & 1 & 4.3 \\
\hline Leiomyoma & 1 & 4.3 \\
\hline Rhabdomyoma & 2 & 8.7 \\
\hline Inflammatory Myofibroblastic & 1 & 4.3 \\
\hline Tumour & 23 & $\mathbf{1 0 0 . 0}$ \\
\hline Total & Table 3. Distribution of the Soft Tissue Tumours of the \\
\hline \multicolumn{2}{|c|}{ Mediastinum } \\
\hline
\end{tabular}

The most common mesenchymal tumours were of neurogenic in origin located in the posterior mediastinum followed by the anterior compartment tumours (lipoma, thymolipoma, rhabdomyoma and spindle cell tumours) (Table 3). 
The ectopic tumours were seen in the $3^{\text {rd }}$ to $5^{\text {th }}$ decade (one case each of ectopic parathyroid in the thymus, parathyroid adenoma, parathyroid carcinoma and ectopic thyroid tissue in the thymus). The most common presentation was hyperparathyroidism by ectopic parathyroid tissues.

There were 8 cases of metastasis to the mediastinum in the age decades $5^{\text {th }}-8^{\text {th }}$ with pressure symptoms being the most common presentation. Metastasis from small cell carcinoma lung, adenocarcinoma, papillary carcinoma thyroid and an anaplastic thyroid carcinoma were seen.

The non-neoplastic lesions included 54 cases with $\mathrm{M}$ : F ratio of 0.93: 1 . They had a varied presentation with 53\% presenting with pressure symptoms followed by PNS, hypercalcaemia, swelling and neurological manifestations; $50 \%$ were in the anterior followed by the middle mediastinum (Figure 6).

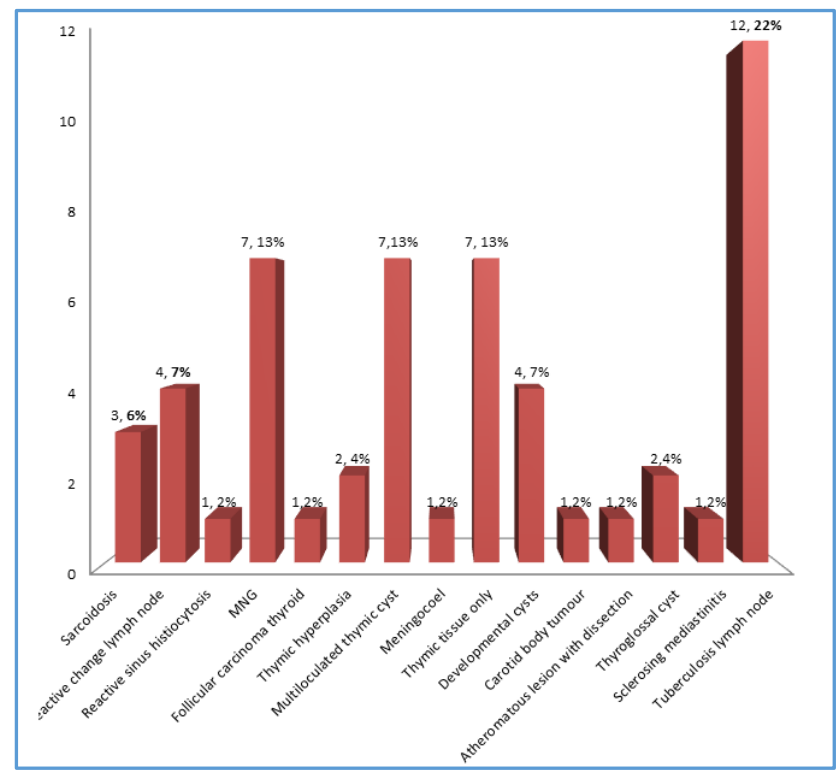

Figure 6. Frequency and Distribution of the Non-Neoplastic Lesions of the Mediastinum

Tuberculous lymphadenopathy was seen on the $3^{\text {rd }}-6^{\text {th }}$ decades. The $1^{\text {st }}$ and the $2^{\text {nd }}$ decade lesions were thymic hyperplasia, normal thymic tissue (for myasthenia gravis), multiloculated thymic cysts, developmental cysts, thyroglossal cysts and reactive changes in lymph nodes. Sarcoidosis was seen in the $3^{\text {rd }}$ and $4^{\text {th }}$ decade, while extension of MNG into the anterior and superior mediastinum was seen in the $3^{\text {rd }}$ to $6^{\text {th }}$ decades.

\section{DISCUSSION}

The mediastinum is a relatively small anatomic compartment accounting for less than $3 \%$ of the thoracic tumours, but show an impressive diversity of both non-neoplastic and neoplastic proliferations like somatic epithelial, lymphoid, mesenchymal and germ cell types. ${ }^{1,3}$

Our study included 157 mediastinal lesions received over a period of 5 years. The peak age of these lesions were in the $4^{\text {th }}$ and $5^{\text {th }}$ decades and they had an approximate M: F ratio of 1: 1 . This was in concordance with the studies conducted independently by Dasgupta et al and Shrivastava et al.4,5

In this study $66 \%$ (103) of the lesions were found in the anterior mediastinum, $12 \%$ (33) in the middle mediastinum,
$8 \%(13)$ in the posterior mediastinum and 5\% (8) in the superior mediastinum. A similar study by Sharma et al showed $36.7 \%$ involvement of the anterior compartment followed by middle (33\%) and posterior (30\%). ${ }^{6}$

$95 \%$ of the cases were symptomatic; 8 cases were detected incidentally. Dubashi et al and Sharma et al reported a similar incidence of $97 \%$ with other studies reporting a range of $60 \%$ - 88\% ${ }^{6,7}$ However, study by Davis et al in 1987 had a higher number of incidentally reported cases (38\%). ${ }^{8}$ This may be due to the recent advancements in the diagnosis of the mediastinal neoplasms by various invasive and noninvasive methods.

The most common presenting symptoms were pressure symptoms (65\%) followed by paraneoplastic symptoms like myasthenia gravis and red cell aplasia (13\%). This was in concordance with Shrivastava et al and Bastos et al.5,9 Hypercalcaemia and Hyperparathyroidism was seen in the ectopic parathyroid tumours of the thymus.

Among the tumours, the thymic epithelial tumours (48 cases) were the most common tumours. This was in concordance with study by Shrivastava et al. ${ }^{5}$ They showed a M: F ratio of 1: 0.9 with majority $79 \%$ (38 cases) presenting with pressure symptoms like cough, dyspnoea and vague chest discomfort, while $21 \%$ (10) of them presented with paraneoplastic syndromes like myasthenia gravis. Most of them were in the anterior mediastinum $(46,95.8 \%)$ and two cases showed extension to the superior mediastinum (2, $4.2 \%$ ). $75 \%$ of the cases were in the age group of $20-50$ years.

$\mathrm{AB}$ thymomas $(18,38 \%)$ were the most common thymomas followed by A, B1, B2 and B3 and a case of sclerosing thymoma. There were 8 cases of thymic carcinoma, 2 cases of sarcomatoid carcinoma, 1 case of hepatoid carcinoma, atypical carcinoid and large cell neuroendocrine carcinoma each. Some of these newer entities were reclassified according to the recent WHO. Most of the thymomas were Masaoka stage 1 or 2 .

Thymic tumours were followed by soft tissue tumours, germ cell tumours, metastasis and lymphomas. The relative frequencies of these broad categories were different as compared to studies by Shrivastava et al and Sharma et al. This could be due to geographic differences seen between the two centres.

Soft tissue tumours comprised of $15 \%$ of the mediastinal tumours. Of the 23 soft tissue tumours analysed, $61 \%$ were seen in males. Pressure symptoms were the most common presentation followed by chest pain; 78\% were benign, while $22 \%$ were malignant. The most common soft tissue tumours were neurogenic (schwannoma, MPNST, ganglioneuroma, neuroblastoma), majority were situated in the posterior mediastinum. These findings were similar to study done by Singh et al and Dasgupta et al. ${ }^{10}$ An extensive review article of mediastinal mesenchymal lesions by Michael A. Den Bakker, Alexander Marx, Kiyoshi Mukai and Philipp Ströbel described 20 soft tissue tumours of the mediastinum and had similar findings as our study. ${ }^{11,12}$

All germ cell tumours were detected in the anterior mediastinum, the most common case being benign cystic teratoma. An interesting case encountered in our study was a mixed malignant germ cell tumour with yolk sac and immature teratomatous components seen in a 38-year-old male. Literature review states that primary mediastinal non- 
seminomatous germ cell tumours are primarily a disease of children and young men, usually presenting in the second to fourth decades of life. The 28-year retrospective study conducted in the Memorial Sloan Kettering Cancer Centre among non-seminomatous germ cell tumours by Inderpal S. Sarkaria et al concludes that the most common type being mixed primary mediastinal non-seminomatous germ cell tumours. Mediastinal origin of NSGCTs is in and of itself considered an independent predictor of poor prognosis compared with those of gonadal origin. Although rare, the diagnosis should be considered in any young male with an anterior mediastinal mass and may represent up to $5 \%$ of anterior mediastinal masses in adults and $10 \%$ to $15 \%$ in children. Hence, meticulous search for more components of germ cell should be done. ${ }^{13}$

Majority of the lymphomas were situated in the middle mediastinum- three cases of Hodgkin's lymphoma and one case each of PMLBCL, ALK + ALCL and a Grey zone Lymphoma- B Cell lymphoma unclassifiable with features of DLBCL and Hodgkin's lymphoma. This was in concordance with independent studies by Dasgupta et al.14

Metastasis was seen in $5^{\text {th }}-8^{\text {th }}$ decades from small cell carcinoma lung, adenocarcinoma, papillary carcinoma thyroid and anaplastic thyroid carcinoma.

Non-neoplastic lesions accounted for $34 \%$ of the lesions. Tuberculous lymphadenopathy was seen in $22 \%$ of the cases (middle mediastinum) followed by MNG (superior and anterior mediastinum). Multiloculated thymic cysts, thymic tissue and thymic hyperplasia presented with paraneoplastic syndromes. These findings were reflected by a similar study by Petkar, Vaideeshvar and Deshpande done in 2001.15 Other lesions include sarcoidosis, reactive changes in lymph node, reactive sinus histiocytosis, meningocoele, follicular carcinoma thyroid (extension only, no metastasis to the superior mediastinum) developmental cysts, carotid body tumour, thyroglossal cyst and sclerosing mediastinitis.

\section{CONCLUSION}

Mediastinal lesions although uncommon comprise of a varied spectrum of tumours ranging from non-neoplastic to benign to the frankly malignant ones. Further studies using larger cohort are warranted to enrich our knowledge regarding these enigmatic tumours.

\section{REFERENCES}

[1] Rosai J. Rosai and Ackerman's surgical pathology. Mediastinum. Chapter 8. Vol I. $10^{\text {th }}$ edn. Elsevier 2011:437-72.

[2] Travis WD, Brambilla E, Burke AP, et al. WHO classification of the tumours of the lung, pleura, thymus and heart. $4^{\text {th }}$ edn. IARC: Lyon 2015.
[3] Aroor AR, Prakasha SR, Seshadri S, et al. A study of clinical characteristics of mediastinal mass. J Clin Diagn Res 2014;8(2):77-80.

[4] Dasgupta S, Bose D, Bhattacharyya NK, et al. A clinicopathological study of mediastinal masses operated in a tertiary care hospital in Eastern India in 3 years with special reference to thymoma. Indian J Pathol Microbiol 2016;59(1):20-4.

[5] Shrivastava CP, Devgarha S, Ahlawat V. Mediastinal tumors: a clinicopathological analysis. Asian Cardiovasc Thorac Ann 2006;14(2):102-4.

[6] Sharma P, Jha V, Kumar N, et al. Clinicopathological analysis of mediastinal masses: a mixed bag of nonneoplastic and neoplastic etiologies. Turk Patoloji Derg 2017;33(1):37-46.

[7] Dubashi B, Cyriac S, Tenali SG. Clinicopathological analysis and outcome of primary mediastinal malignancies-a report of 91 cases from a single institute. Ann Thorac Med 2009;4(3):140-2.

[8] Davis RD, Oldham HN, Sabiston DC. Primary cysts and neoplasms of the mediastinum: recent changes in clinical presentation, methods of diagnosis, management and results. Ann Thorac Surg 1987;44(3):229-37.

[9] Bastos P, Magalhaes A, Fernandes G, et al. Primary cysts and tumours of the mediastinum cistos e tumores primários do mediastino. Rev Port Pneumol 2007;13(5):659-73.

[10] Singh G, Amin Z, Wuryantoro, et al. Profile and factors associated with mortality in mediastinal mass during hospitalization at Cipto Mangunkusmo Hospital, Jakarta. Acta Med Indones 2013;45(1):3-10.

[11] den Bakker MA, Marx A, Mukai K, et al. Mesenchymal tumours of the mediastinum--part I. Virchows Arch 2015;467(5):487-500.

[12] den Bakker MA, Marx A, Mukai K, et al. Mesenchymal tumours of the mediastinum--part II. Virchows Arch 2015;467(5):501-17.

[13] Sarkaria IS, Bains MS, Sood S, et al. Resection of primary mediastinal non-seminomatous germ cell tumors: a 28-year experience at memorial sloankettering cancer center. J Thorac Oncol 2011;6(7):1236-41.

[14] Shamsuddin F, Khadilkar UN, Saha D. Unusual lesions of the mediastinum. Lung India 2015;32(6):566-71.

[15] Petkar M, Vaideeswar P, Deshpande JR. Surgical pathology of cystic lesions of the mediastinum. J Postgrad Med 2001;47(4):235-9. 